\title{
High dietary protein decreases fat deposition induced by high-fat and high-sucrose diet in rats
}

\author{
Catherine Chaumontet ${ }^{1,2}$, Patrick C. Even ${ }^{1,2}$, Jessica Schwarz ${ }^{3,4}$, Angélique Simonin-Foucault ${ }^{1,2}$, \\ Julien Piedcoq ${ }^{1,2}$, Gilles Fromentin ${ }^{1,2}$, Dalila Azzout-Marniche ${ }^{1,2 *}$ and Daniel Tomé ${ }^{1,2}$ \\ ${ }^{1}$ INRA, CRNH-IdF, UMR914 Nutrition Physiology and Ingestive Behavior, Paris F-75005, France \\ ${ }^{2}$ AgroParisTech, CRNH-IdF, UMR914 Nutrition Physiology and Ingestive Behavior, Paris F-75005, France \\ ${ }^{3}$ Nutrition, Metabolism and Genomics Group, Division of Human Nutrition, Wageningen University, 6703 HD Wageningen, \\ The Netherlands \\ ${ }^{4}$ Netherlands Nutrigenomics Centre, 6703 HD Wageningen, The Netherlands \\ (Submitted 26 June 2014 - Final revision received 10 May 2015 - Accepted 2 June 2015 - First published online 19 August 2015)
}

\section{Abstract}

High-protein diets are known to reduce adiposity in the context of high carbohydrate and Western diets. However, few studies have investigated the specific high-protein effect on lipogenesis induced by a high-sucrose (HS) diet or fat deposition induced by high-fat feeding. We aimed to determine the effects of high protein intake on the development of fat deposition and partitioning in response to high-fat and/or HS feeding. A total of thirty adult male Wistar rats were assigned to one of the six dietary regimens with low and high protein, sucrose and fat contents for 5 weeks. Body weight (BW) and food intake were measured weekly. Oral glucose tolerance tests and meal tolerance tests were performed after 4th and 5th weeks of the regimen, respectively. At the end of the study, the rats were killed $2 \mathrm{~h}$ after ingestion of a calibrated meal. Blood, tissues and organs were collected for analysis of circulating metabolites and hormones, body composition and mRNA expression in the liver and adipose tissues. No changes were observed in cumulative energy intake and BW gain after 5 weeks of dietary treatment. However, high-protein diets reduced by $20 \%$ the adiposity gain induced by HS and high-sucrose high-fat (HS-HF) diets. Gene expression and transcriptomic analysis suggested that high protein intake reduced liver capacity for lipogenesis by reducing mRNA expressions of fatty acid synthase (fasn), acetyl-CoA carboxylase a and b (Acaca and Acacb) and sterol regulatory element binding transcription factor 1c (Srebf-1c). Moreover, ketogenesis, as indicated by plasma $\beta$-hydroxybutyrate levels, was higher in HS-HF-fed mice that were also fed high protein levels. Taken together, these results suggest that high-protein diets may reduce adiposity by inhibiting lipogenesis and stimulating ketogenesis in the liver.

Key words: High protein intake: Fat deposition: Liver lipogenesis: Liver transcriptomic analysis

Increasing dietary protein reduces lipid accumulation in the liver ${ }^{(1-4)}$ and in the adipose tissue (AT) ${ }^{(2,5)}$. These effects have been attributed to a reduced energy intake due to the satiating effect of proteins ${ }^{(6,7)}$, but it was also observed in pair-fed rats ${ }^{(8)}$ and in ad libitum-fed mice ${ }^{(1)}$ that a reduced fat mass can be observed without differences in energy intake. Accordingly, the decrease in adiposity was also attributed to a specific lowering effect of dietary protein on both de novo fatty acid (FA) synthesis and direct dietary FA accumulation as TAG in the liver and AT. Results from different studies showed that increasing protein at the expense of carbohydrates reduces expression of fatty acid synthase (Fasn) in rats and of acetyl-CoA carboxylase in AT in rats and pigs ${ }^{(8-11)}$. Moreover, increasing the protein content of the diet in rats and mice fed high-fat (HF) and high-sucrose (HS) diets reduces body weight (BW) and adiposity and decreases hepatic TAG accumulation by enhancing liver lipid secretion into VLDL particles $^{(1,12)}$. In this context, the aim of the present study was to investigate the effect of increasing the protein content of the diet on the deposition of fat originating from diet or lipogenesis. For this purpose, this study evaluated the effect of increasing protein intake in rats fed an HS or a high-sucrose high-fat (HS-HF) diet on food intake, lipid accumulation, glucose tolerance and gene expression in the liver and AT as well as signalling in the hypothalamus. In order to characterise the mechanisms involved in fat deposition and partitioning, these effects were investigated during the development of fat deposition.

Abbreviations: AA, amino acid; AT, adipose tissue; $\beta$-HB, $\beta$-hydroxybutyrate; BW, body weight; FA, fatty acid; Fasn, fatty acid synthase; HP, high protein intake; $\mathrm{HF}$, high fat; HS, high sucrose; NP, normal protein; POMC, pro-opiomelanocortin.

* Corresponding author: D. Azzout-Marniche, fax + 331 44081858, email azzout@agroparistech.fr 


\section{Methods}

\section{Experimental design and diets}

The protocol was approved by the French Ethical Committee (avis saisine Comethea12-020). In all, thirty adult male Wistar rats (Harlan) initially weighing 300-350 g were housed in individual stainless-steel cages in a room with controlled temperature $\left(23 \pm 1^{\circ} \mathrm{C}\right)$ and humidity $(55 \pm 3 \%)$ with an artificial $12 \mathrm{~h}$ light-12 h dark reverse cycle (light off at 22.00 hours). Rats were acclimatised to the laboratory conditions and the diet protocol (with normal protein diet (NP)) for the first $10 \mathrm{~d}$. Rats were accustomed to receiving their food according to a pattern that consisted of a calibrated meal of $87-88 \mathrm{~kJ}$ between 09.00 and 10.00 hours and free access to food between 11.00 and 18.00 hours. This pattern trained the animals to eat a standard meal within $1 \mathrm{~h}$, so as to standardise both the amount of energy ingested and the physiological state of animals that were to be studied in a fed state on the day of the meal test and at the end of the experiment, the day of euthanasia. The animals were then weight-matched and assigned ( $n 5$ per group) to one of the following six dietary regimens: two control (C) regimens with either an NP or high protein (HP) content (NP-C, HP-C), two HS regimens with either NP or HP content (NP-HS, HP-HS) and two HS-HF regimens with either NP or HP content (NP-HS-HF, HP-HS-HF) (Table 1). The animals were fed their respective diets for 5 weeks with free access to water.

\section{Measure of food intake and body weight}

The diet was moistened to minimise spillage, and the food containers were refilled daily with fresh food. Food intake was measured by the difference in the food cup weight before and after the feeding period (11.00-18.00 hours); $5 \mathrm{~d}$ before exposure to the respective diets, food intake was measured to obtain baseline values. Food intake was measured $5 \mathrm{~d}$ /week from 1 st week before and then during 3 weeks after exposure to the respective diets. BW was measured $5 \mathrm{~d} /$ week in the morning before giving the calibrated meal during the 5 weeks of the experiment.

\section{Oral glucose tolerance test}

The oral glucose tolerance test (OGTT) was performed during the 4th week. On the day of the test, after an overnight fast, rats received orally $100 \mu \mathrm{l} / 100 \mathrm{~g}$ of $\mathrm{BW}$ glucose solution at a concentration of $1 \mathrm{~g} / \mathrm{l}$. Blood samples were collected from the tail vein before the test and 15, 30, 60, 90 and $120 \mathrm{~min}$ after administration of glucose solution. Blood glucose and plasma insulin levels were measured as described in analytical procedures and determination ${ }^{(13)}$.

\section{Meal tolerance test}

Meal tolerance tests were conducted between 09.00 and 13.00 hours on the day of euthanasia. Rats were fasted overnight and a calibrated meal of their respective diets was fed immediately after blood sampling. Blood glucose, plasma biochemical and hormonal changes in response to the meal were monitored for $2 \mathrm{~h}$ after the meal at 30,60 and $120 \mathrm{~min}$. Data are presented as mean values with their standard deviations for fasting values and AUC for kinetics.

\section{Tissue sampling and body composition analysis}

At the end of the experiment, rats were euthanised $2 \mathrm{~h}$ after ingestion of their calibrated meal. Rats were deeply anaesthetised with an overdose of pentobarbital $(50 \mathrm{mg} / \mathrm{kg})$ and decapitated. The main tissues and organs (liver, spleen, kidneys, brain, heart, skin as well as subcutaneous (SCAT), retroperitoneal (RAT), epididymal (EAT) and mesenteric (MAT) AT) were collected, blot-dried and weighed to the nearest 0.01 g. Liver, hypothalamus and TAE aliquots were snap-frozen in liquid nitrogen and stored at $-80^{\circ} \mathrm{C}$ until RNA extraction.

\section{Analytical procedures and determination}

The blood samples were collected on EDTA, immediately centrifuged and the plasma aliquots for biochemical or hormonal analysis were stored at $-70^{\circ} \mathrm{C}$ until assayed. All plasma biochemical analyses (albumin, lactate, cholesterol,

Table 1. Composition of the diets

\begin{tabular}{|c|c|c|c|c|c|c|}
\hline & NP-C ${ }^{*}$ & $\mathrm{HP}-\mathrm{C}^{\star}$ & NP-HS & HP-HS & NP-HS-HF & HP-HS-HF \\
\hline \multicolumn{7}{|l|}{ g/kg DM } \\
\hline Protein $†$ & 140 & 530 & 140 & 484 & 160 & 580 \\
\hline Sucrose & $100 \cdot 3$ & $45 \cdot 7$ & 361.35 & $189 \cdot 35$ & 291.3 & 80 \\
\hline Maize starch & $622 \cdot 4$ & 287 & $361 \cdot 35$ & $189 \cdot 35$ & 391.4 & 80 \\
\hline Soya oil & 40 & 40 & 40 & 40 & 40 & 40 \\
\hline Palm oil & 0 & 0 & 0 & 0 & 120 & $122 \cdot 82$ \\
\hline Minerals (AIN-93M)‡ & 35 & 35 & 35 & 35 & 35 & 35 \\
\hline Vitamins (AIN-93M)‡ & 10 & 10 & 10 & 10 & 10 & 10 \\
\hline Cellulose & 50 & 50 & 50 & 50 & 50 & 50 \\
\hline Choline & $2 \cdot 3$ & $2 \cdot 3$ & $2 \cdot 3$ & $2 \cdot 3$ & $2 \cdot 3$ & $2 \cdot 3$ \\
\hline \multicolumn{7}{|l|}{ Percentage of energy } \\
\hline Total protein & 14.7 & $55 \cdot 6$ & $14 \cdot 7$ & $52 \cdot 4$ & 14.5 & 52.4 \\
\hline Total fat & 9.4 & 9.4 & 9.4 & 9.4 & $32 \cdot 7$ & 33.1 \\
\hline Total carbohydrate & 75.8 & 34.9 & $75 \cdot 8$ & 39.8 & $52 \cdot 8$ & 14.4 \\
\hline Metabolisable energy ( $\mathrm{kJ} / \mathrm{g}$ DM) & 15.95 & 15.95 & 15.95 & 15.95 & 18.46 & 18.52 \\
\hline
\end{tabular}

* Dietary treatment: NP, normal protein; C, control; HP, high protein; HS, high sucrose; HF, high fat

$\dagger$ Total milk protein isolate, purchased from Nutrinov.

‡ ICN Biochemicals. 
HDL-cholesterol, TAG, free fatty acid (FFA), glycerol and $\beta$-hydroxybutyrate $(\beta$-HB)) were performed using an Olympus AU 400 robot specifically calibrated for rat assays (Centre d' Explorations Fonctionnelles Intégrées). Plasma insulin was detected using ELISA (Mercodia Rat Insulin; Mercodia AB). Plasma glucagon, leptin and ghrelin concentrations were assessed by Luminex (Bio-Plex Pro ${ }^{\text {TM }}$ rat standard; Bio-Rad). Blood glucose level was determined immediately after sampling with a blood glucose meter (Accu-Chek Go). Liver TAG levels were determined using an enzymatic assay (TG-TIGS kit; Randox).

\section{Ribonucleic acid extraction and real-time RT-PCR analysis}

Total RNA was extracted from the liver, AT and hypothalamus tissue with TRIzol reagent (Invitrogen). Concentrations of the RNA samples were determined using a NanoDrop ND-1000 UV-Vis spectrophotometer (Isogen). RNA integrity was confirmed by ethidium bromide staining; $0.4 \mu \mathrm{g}$ of total RNA in a final volume of $10 \mu \mathrm{l}$ was reverse transcribed using HighCapacity cDNA Archive Kit Protocol (Applied Biosystems). mRNA concentration was determined by real time on the ABI 7300 (Applied Biosystems) using Power Sybr Green PCR master mix (Applied Biosystems) as previously described ${ }^{(9)}$. For each run, the efficiency and the possible contaminations were checked. The primer sequences of target genes are detailed in online Supplementary Table S1. Gene expression was calculated as follows: $2^{-\Delta \Delta C t}$ relatively to the NP-C group and $18 \mathrm{~S}$ RNA was used as the housekeeping gene. Data are presented as mean values with their standard deviations.

\section{Rat liver transcriptome: microarray analysis}

After extraction, total RNA was purified using SV total RNA isolation system (Promega). Total purified liver RNA of five rats per group was subsequently pooled at a concentration of $1500 \mathrm{ng} / \mathrm{rat}$. Quality of the pooled RNA was assessed using Agilent 2100 Bioanalyzer with RNA 6000 Nano Chips using the Eukaryote Total RNA Nano assay (Agilent Technologies). RNA quality was considered as sufficient for array hybridisation if the RNA integrity number was $\geq 7 \cdot 0$. The Ambion WT Expression kit (Life Technologies), in conjunction with the Affymetrix GeneChip WT Terminal Labelling kit (Affymetrix), was used for the preparation of labelled cDNA from 100 ng of total RNA without rRNA reduction. RNA (100 ng) was labelled with the Whole Transcript Sense Target Assay (Affymetrix). Hybridisation, washing and scanning of Affymetrix Rat Gene 1.0 ST (Affymetrix) array was carried out according to standard Affymetrix protocols. Quality control and normalisation were performed using Bioconductor Packages integrated in an online pipeline ${ }^{(14)}$. Probe sets were redefined according to Dai et al. ${ }^{(15)}$. Normalised expression estimates of probe sets were computed using the robust multiarray analysis algorithm available in the Bioconductor library AffyPLM using default settings ${ }^{(16)}$. Array data have been submitted to the Gene Expression Omnibus and are available under accession number GSE47570. To detect an effect of the increased protein content of the diets, fold changes of signal intensities were calculated as signal $\log$ ratios (HP-NP) for each of the background diets. Fold changes of $>0.25$ or $<-0.25$ were considered as biologically relevant.

\section{Statistics}

Data are expressed as mean values with their standard deviations in tables or standard errors in figures for kinetics. The effect of the amount of protein in the diet (normal $v$. high) and the interaction with dietary lipid and sucrose levels (low $v$. high) were analysed by ANOVA using the generalised linear model procedure of SAS (version 9.1; SAS Inc.). Kinetics were analysed using SAS mixed models for repeated measurements. The effects of dietary fat or sucrose (S) levels and their interactions or their interaction with protein and the effect of time $(t)$ are indicated when significant. $P<0.05$ was considered significant and $0.05<P<0.1$ was considered to indicate a tendency. Post hoc Tukey tests for multiple comparisons were performed to make pairwise comparisons.

\section{Results}

Effect of high protein intake on food intake, body weight and body composition

No difference in cumulative food intake over the 5 weeks of dietary treatment and no differences in final BW were observed between groups (data not shown). However, the protein content of the diets significantly affected the evolution of the rats' BW as BW was lower in groups fed HP diets between the 2 nd and the 3 rd week of the regimen (Fig. 1). Moreover, the effect of protein depended on the sucrose content of the diet as the BW level was greater in the groups fed an HS diet $(\mathrm{P} \times \mathrm{S} \times \mathrm{d}$ $P=0 \cdot 007)$ compared with the control group.

Analysis of body composition showed no effect on liver weight (Fig. 2(a)), whereas the weight of all dissected fat pads was significantly reduced in rats fed HP diets (Fig. 2(b) and (c)). These effects were also observed for the ratio of AT/weight on total BW (white AT, $P=0 \cdot 01$; MAT, $P=0.0005$; SCAT, $P=0.02$, a tendency for EAT, $P=0.06$ and RAT, $P=0.06$ ).

\section{Effect of high protein intake on plasma ghrelin and leptin}

In the fasted state, the HP diets did not affect plasma ghrelin but reduced plasma leptin levels in HS-HF-fed rats (Table 2). In response to the meal test, $\mathrm{HP}$ diets reduced plasma leptin and ghrelin levels under HS and HF conditions (Fig. 3(a) and (b)).

\section{Effect of high protein intake on glucose homoeostasis}

In the fasted state, no effect of the composition of the diet was observed on glycaemia, insulinaemia and glucagonaemia (Table 2). After the meal, glycaemia blood glucose was higher in the HS groups than in $C$ groups (sucrose effect $P=0.02$ for glycaemia kinetic) (Fig. 4(a)) without any effect on plasma insulin and glucagon levels (Fig. 4(b) and (c)). Nevertheless, the insulin to glucagon ratio was $70 \%$ higher $(P=0.01$ for sucrose effect) in NP-HS than in the NP-C group $(0.07 \pm 0.025$ and $0 \cdot 114 \pm 0 \cdot 042$ in the NP-C and the NP-HS group, respectively). Blood glucose tended to be lower in the HP than in the NP groups $(P=0.08$ for kinetics and $P=0.054$ for AUC) (Fig. 4(a) and $(d)$ ), whereas the protein content of the diet had no effect on plasma insulin levels (Fig. 4(b) and (e)). In contrast to 


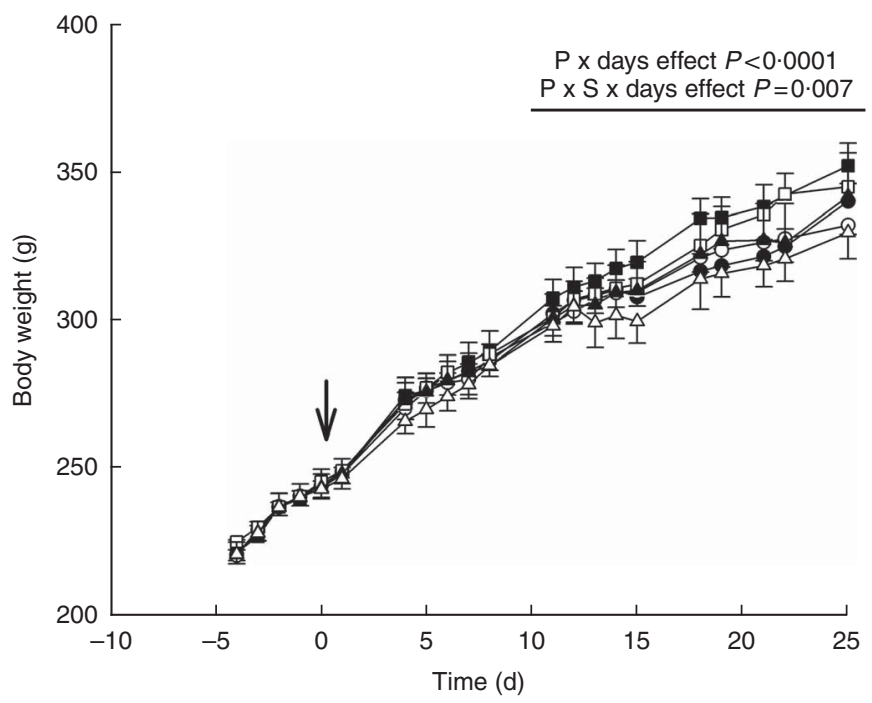

Fig. 1. Effect of increased protein content of the diet on the ability of sucrose and/or fat to increase body weight in rats. Rats were fed a normal protein (NP) diet or a high-protein (HP) diet for 5 weeks, containing a normal amount of sucrose and fat (control), high sucrose (HS) or high sucrose high-fat (HS-HF) diets (see the 'Methods' section for details of diet composition). Body weight was followed-up during the experiment from the 1st week before the beginning of the experiment until the 4 th week and was also measured at the end of the experiment. Results are given as mean values with their standard deviations $(n 5)$. The main statistical effects are indicated on each graph: the $P$ value is indicated when the difference was or tended to be significant. $P$, protein effect; $F$, fat effect; $S$, sucrose effect; $P \times F$, interaction between NP-HS-HF and HP-HS-HF; P $\times$ C, interaction between NP-HS and HP-HS. NS indicates no significant statistical effect $(P>0.05)$. $-\longrightarrow, \mathrm{NP}$; $-\bigcirc-$, HP; $\longrightarrow$ - NP-HS; $\square-$ HP-HS; $\longrightarrow$, NP-HSHF; $\backsim$, HP-HSHF.

(a)

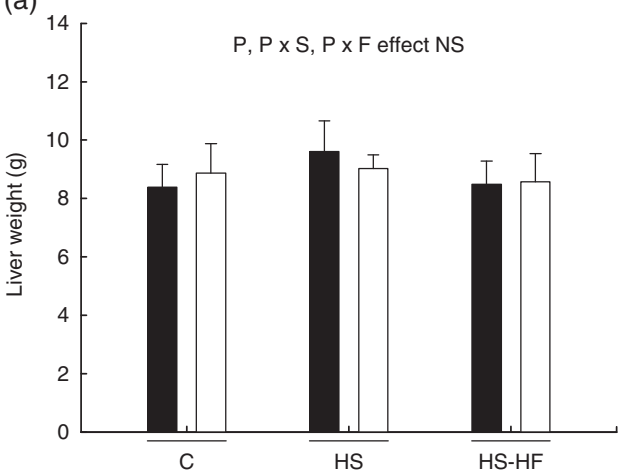

(b)

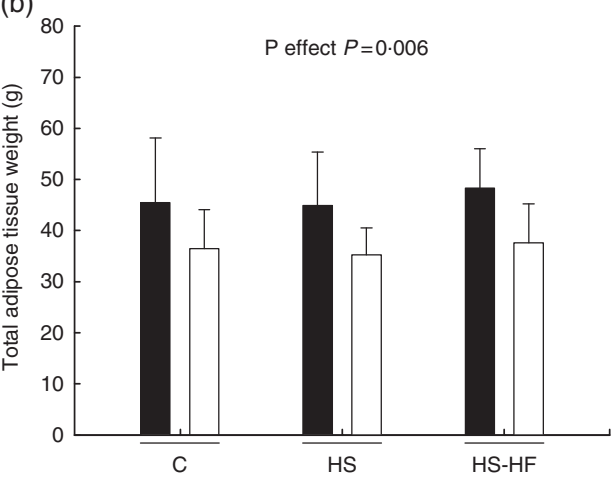

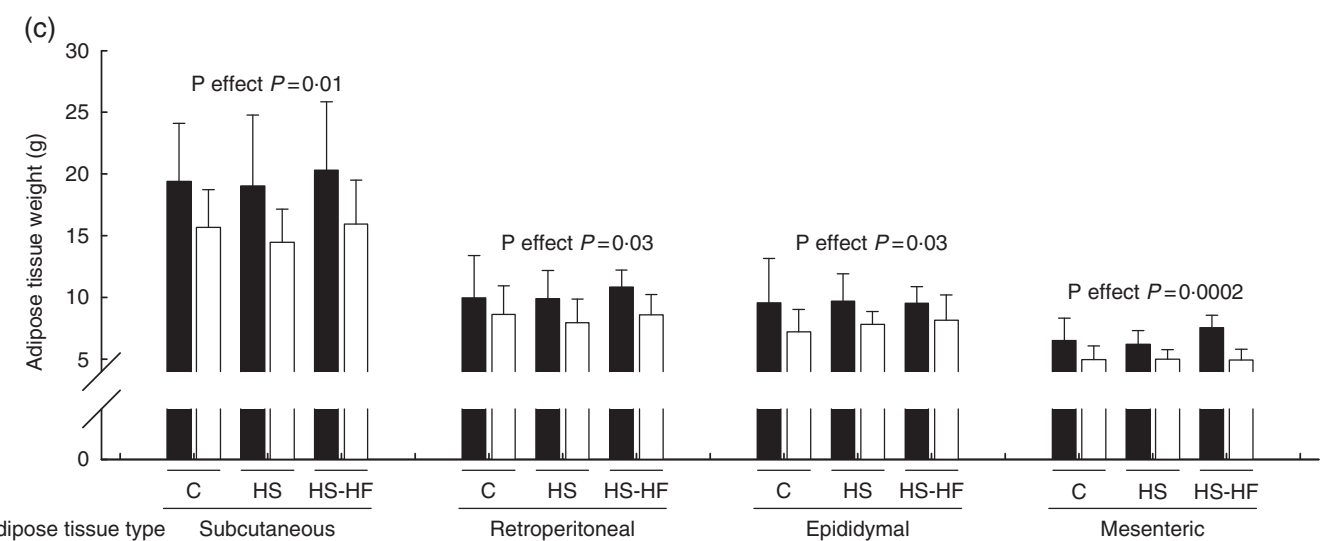

Fig. 2. Effect of high protein intake on body composition. (a) The weight of the liver, (b) total adiposity and (c) each fat pad was measured at the end of the experiment by body composition analysis. Results are given as mean values with their standard deviations $(n 5)$. The main statistical effects are indicated on each graph: the $P$ value is indicated when the difference was or tended to be significant. P, protein effect; $F$, fat effect; $S$, sucrose effect; NP, normal protein; HS, high sucrose; HF, high fat; HP, high protein; HF, high fat; $\mathrm{P} \times \mathrm{F}$, interaction between NP-HS-HF and HP-HS-HF; $\mathrm{P} \times \mathrm{C}$, interaction between NP-HS and HP-HS. NS indicates no significant statistical effect $(P>0.05)$. NP; $\longleftarrow$, HP. 
Table 2. Effect of high-protein (HP) diet on plasma parameters in fasted state (Mean values and standard deviations; $n$ )

\begin{tabular}{|c|c|c|c|c|c|c|c|c|c|c|c|c|c|}
\hline & \multicolumn{6}{|c|}{$\mathrm{NP}^{*}$} & \multicolumn{6}{|c|}{$\mathrm{HP}^{*}$} & \multirow[b]{3}{*}{ Statistical effect $\dagger$} \\
\hline & \multicolumn{2}{|c|}{$\mathrm{C}^{*}$} & \multicolumn{2}{|c|}{$\mathrm{HS}^{*}$} & \multicolumn{2}{|c|}{ HS-HF* } & \multicolumn{2}{|c|}{$\mathrm{C}^{*}$} & \multicolumn{2}{|c|}{$\mathrm{HS}^{*}$} & \multicolumn{2}{|c|}{ HS-HF* } & \\
\hline & Mean & SD & Mean & SD & Mean & SD & Mean & SD & Mean & SD & Mean & SD & \\
\hline Glycaemia (g/l) & 1.04 & 0.87 & $1 \cdot 10$ & 0.11 & $1 \cdot 12$ & 0.37 & 1.06 & 0.13 & 1.04 & 0.08 & $1 \cdot 10$ & 0.13 & NS \\
\hline Glycerol $(\mu \mathrm{mol} / \mathrm{l})$ & $305 \cdot 9$ & $33 \cdot 2$ & $315 \cdot 8$ & $90 \cdot 0$ & $300 \cdot 0$ & $36 \cdot 3$ & $266 \cdot 2$ & $40 \cdot 9$ & $271 \cdot 8$ & $52 \cdot 2$ & $295 \cdot 8$ & $60 \cdot 7$ & NS \\
\hline TAG $(\mathrm{mmol} / \mathrm{l})$ & 0.94 & 0.18 & 1.03 & 0.44 & 1.08 & 0.32 & 0.59 & 0.08 & 0.64 & 0.13 & 0.63 & 0.12 & $\mathrm{P}(P<0.001)$ \\
\hline Albumin $(\mathrm{g} / \mathrm{l})$ & 39.5 & 2.5 & $41 \cdot 2$ & 1.7 & $40 \cdot 1$ & $1 \cdot 1$ & $39 \cdot 8$ & 1.6 & 39.8 & 1.5 & $37 \cdot 7$ & 0.9 & NS \\
\hline Lactate $(\mathrm{mmol} / \mathrm{l})$ & $2 \cdot 72$ & 0.79 & $2 \cdot 90$ & 0.94 & 2.98 & 1.45 & $3 \cdot 10$ & 1.67 & $2 \cdot 30$ & 0.60 & $3 \cdot 28$ & $2 \cdot 20$ & NS \\
\hline Cholesterol (mmol/l) & 1.81 & 0.18 & 1.86 & 0.27 & 1.77 & 0.15 & 2.04 & 0.49 & 1.70 & 0.46 & $2 \cdot 10$ & 0.46 & NS \\
\hline HDL-cholesterol (mmol/l) & $1 \cdot 18$ & 0.13 & $1 \cdot 20$ & 0.17 & $1 \cdot 18$ & 0.11 & 1.38 & 0.30 & 1.19 & 0.31 & 1.42 & 0.27 & $P(P<0.05)$ \\
\hline$\beta$-Hydoxybutyrate $(\mathrm{mmol} / \mathrm{l})$ & 0.59 & 0.24 & 0.55 & 0.21 & 0.67 & 0.33 & 0.66 & 0.26 & 0.71 & 0.24 & 0.69 & 0.20 & NS \\
\hline NEFA $(\mathrm{mmol} / \mathrm{l})$ & 1.08 & 0.38 & 0.68 & 0.39 & 0.83 & 0.47 & 0.52 & 0.31 & 0.97 & 0.28 & 0.879 & 0.33 & NS \\
\hline Glucagon (ng/l) & $40 \cdot 4$ & $13 \cdot 6$ & $41 \cdot 3$ & 26 & $40 \cdot 9$ & $19 \cdot 3$ & $57 \cdot 8$ & $6 \cdot 9$ & 43.9 & $12 \cdot 7$ & $48 \cdot 2$ & $29 \cdot 0$ & NS \\
\hline Insulin $(\mu \mathrm{g} / \mathrm{l})$ & 1.28 & 0.77 & 3.03 & 1.66 & 1.28 & 0.77 & $1 \cdot 13$ & 0.81 & 1.81 & $1 \cdot 11$ & $2 \cdot 21$ & 1.64 & NS \\
\hline Leptin $(\mu \mathrm{g} / \mathrm{l})$ & $1 \cdot 14$ & 0.57 & 1.34 & $1 \cdot 13$ & 1.44 & $1 \cdot 16$ & 1.01 & 0.42 & 0.81 & 0.41 & 0.64 & 0.19 & $\mathrm{P} \times \mathrm{F}(P<0.05)$ \\
\hline Ghrelin $(\mu \mathrm{g} / \mathrm{l})$ & $1 \cdot 28$ & 0.46 & 0.88 & 0.61 & 0.49 & 0.32 & 0.63 & 0.54 & 0.45 & 0.17 & 0.39 & 0.19 & NS \\
\hline
\end{tabular}

$\mathrm{P}$, protein effect; $\mathrm{F}$, fat effect; $\mathrm{P} \times \mathrm{F}$, interaction between NP-HS-HF and HP-HS-HF

* Dietary treatment: NP, normal protein; HP; C, control; HS, high sucrose; HF, high fat

† The $P$ value is indicated when the difference was or tended to be significant. NS indicates no significant statistical effect $(P>0.05)$.

plasma insulin, glucagon levels were higher in the HP groups ( $P=0.02$ for kinetics). In accordance with the inhibitory effect of glucose on glucagon secretion, the difference in glucagon concentrations between HP and NP groups was more important when the sucrose content of the diet was lower (Fig. 4(c) and (f)).

In response to the OGTT, no major effect of dietary macronutrient composition was observed on glucose and insulin kinetics, despite different basal values and a lower increase in blood glucose and plasma insulin levels in the HP-HS-HF groups compared with the NP-HS-HF group (online Supplementary Fig. S1). No differences were observed for the AUC.

\section{Effect of high protein intake on plasma lipids and liver TAG}

The fat or sucrose content of the diets had no major effect on plasma biochemical parameters in the fasted state (Table 2). However, after the meal, plasma TAG (+85\%), FFA (+69\%) and $\beta$-HB (+36\%) were significantly higher in the NP-HS-HF group than in the NP-C group (Table 3 ). These results are in accordance with the increase in dietary lipids intake of the NP-HS-HF group. Plasma lactate was significantly lower in the HS-HF groups than in the $\mathrm{C}$ and HS groups $(P=0 \cdot 02)$, which was probably due to the lower carbohydrate content of the HS-HF diet.

In the fasted state, the increase in the protein content of diet also had no major effect on most of the plasma biochemical parameters studied except for TAG and HDL (Table 2). Plasma TAG was lower in the HP groups $(P<0 \cdot 001)$, whereas HDL was greater in the HP-C and the HP-HS-HF $(P<0.05)$ than in the NP groups (Table 3). Plasma TAG concentration was 37, 25 and $47 \%$ lower in the HP-C, HP-HS and HP-HS-HF groups, respectively, than in the respective NP groups (Table 3 ). Plasma $\beta$-HB was greater in all HP groups with the highest value observed in the HP-HS-HF group (+87\% in comparison with NP-HS-HF).

Liver TAG content was not significantly modified by the diets, but there was a tendency for higher liver TAG levels in the
HS-HF groups $(P=0 \cdot 07)$ and lower liver TAG levels in the HP-C and the HP-HS groups than in the NP-C and the NP-HS groups $(P=0 \cdot 08)$. In contrast, liver TAG was similar in the HP-HS-HF and the NP-HS-HF groups (Table 3 ).

Effect of high protein intake on gene expression in the liver, adipose tissue, muscle and hypothalamus (quantitative $P C R$ analysis)

To assess the changes in the control of lipogenesis, the expressions of acetyl-CoA carboxylases (Acaca and Acacb), Fasn and sterol regulatory element binding transcription factor 1 (Srebf-1c) were measured in the liver and in EAT (Table 4). In the liver, mRNA encoding Acaca and Srebf-1c were significantly lower in the HP than in the NP groups (Table 4). Fasn expression was also reduced in the HP than in the NP groups. In the AT, Fasn mRNA $(P=0.04)$ was significantly lower in rats fed the HS-HF diet than in those fed the HC diets, but was not different between rats fed the HP and NP diets. These results suggest that HP feeding decreased lipogenesis in both the liver and the AT. Moreover, no change in AT leptin mRNA levels was observed, which suggests that the lower plasma leptin levels in the HP groups would rather relate to the lower adiposity in these groups.

In the liver, there was no effect of the protein content of the diet on mRNA encoding proteins involved in lipolysis and $\beta$-oxidation (hormone-sensitive lipase (Lipe) in AT and carnitine palmitoyltransferase 1a (Cpt1a), carnitine palmitoyltransferase 2 (Cpt2) and uncoupling protein 2 (Ucp2) in the liver (Table 4)). In parallel, expression of phosphoenolpyruvate carboxykinase 1 (soluble) (Pck1) (encoding the enzyme phosphoenolpyruvate carboxykinase) was induced by HP diets, either by the lipids or by the sucrose content of the diet.

Concerning the main hypothalamic neuropeptides controlling food intake, the mRNA coding the anorexigenic neuromediator pro-opiomelanocortin (POMC) was significantly lower in rats fed 
(a)
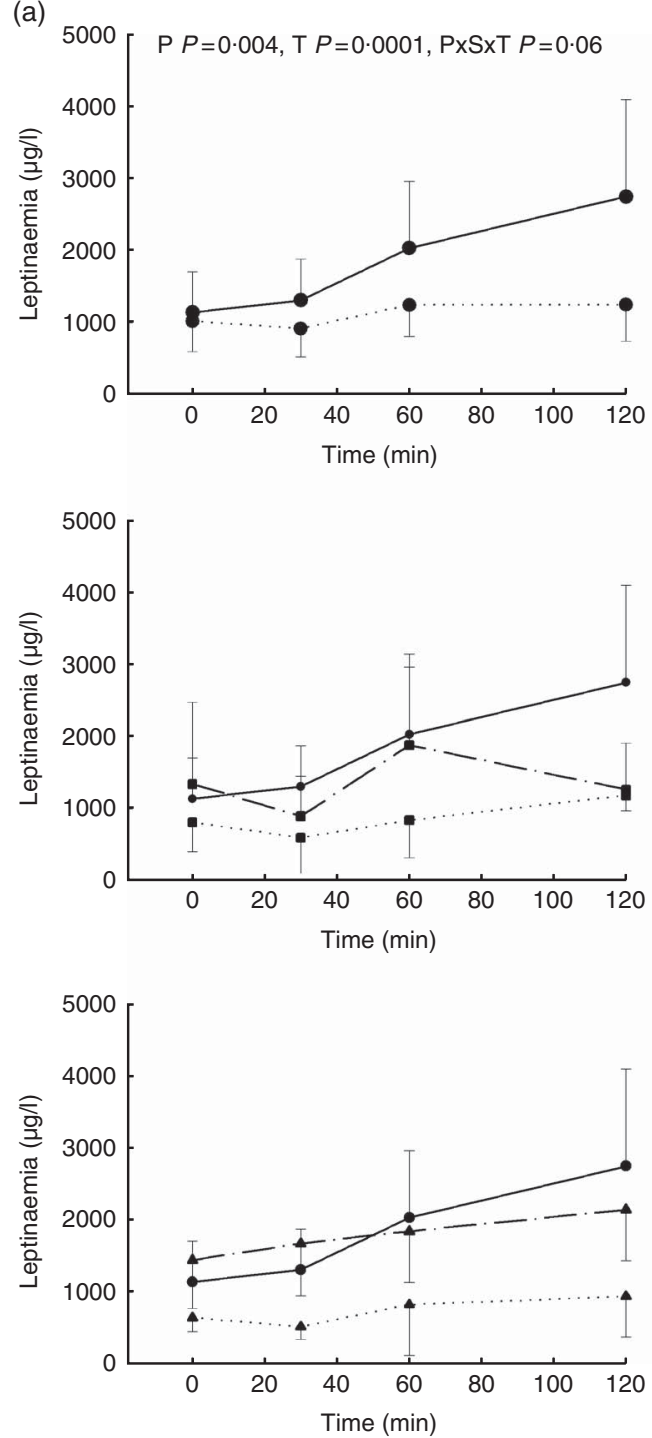

(b)
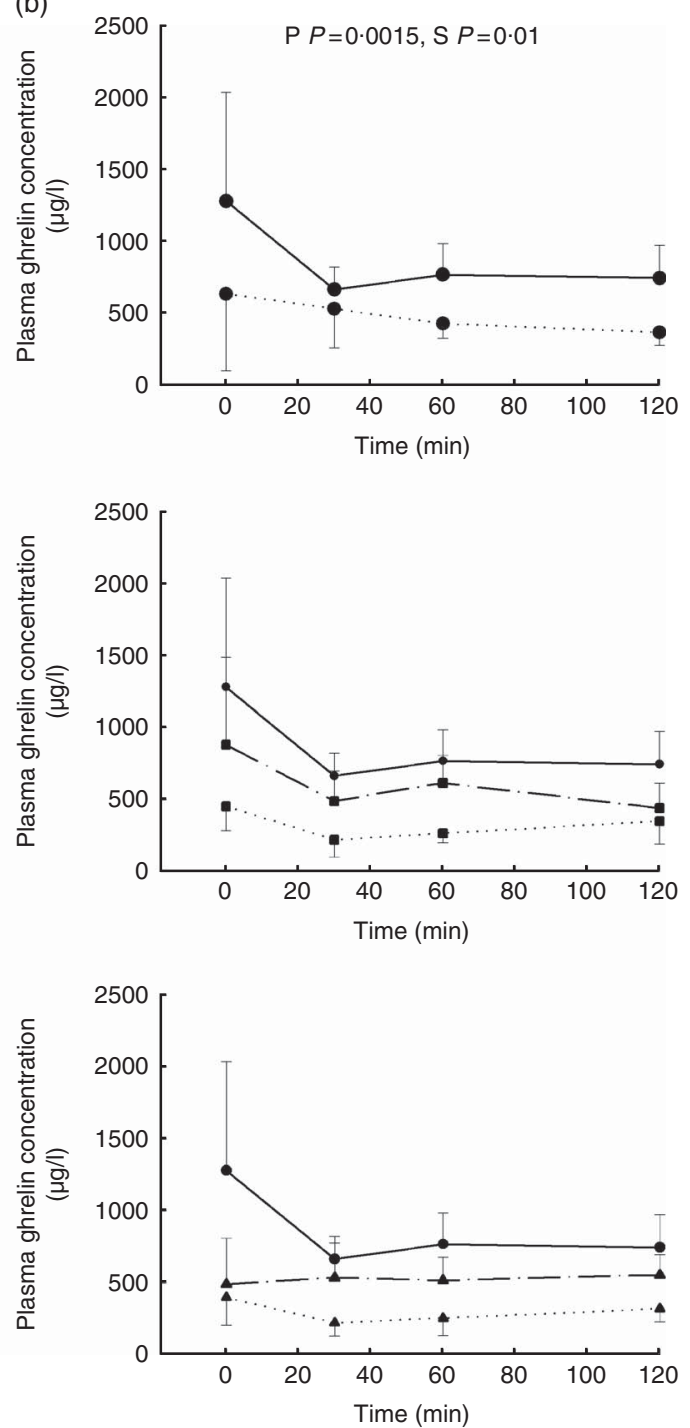

Fig. 3. Effect of high protein intake on leptin and ghrelin kinetics in response to meal intake. From day 33 to 37 , rats were fed a calibrated meal and blood was sampled at $t_{0}$ (fasted state) and 30,60 and 120 min after the meal. Results are given as mean values with their standard error of the mean for (a) leptin and (b) ghrelin kinetics. High protein (HP) groups were compared with normal protein (NP) groups under control (C), high sucrose (HS) or high sucrose and high fat (HS-HF) conditions. The main statistical effects are indicated on each graph: the $P$ value is indicated when the difference was or tended to be significant. $P$, protein effect; $F$, fat effect; $\mathrm{S}$, sucrose effect; $\mathrm{P} \times \mathrm{F}$, interaction between NP-HS-HF and HP-HS-HF; P $\times$ C, interaction between NP-HS and HP-HS. $T$ indicates the effect of time. NS indicates no significant statistical effect $(P>0.05)$.

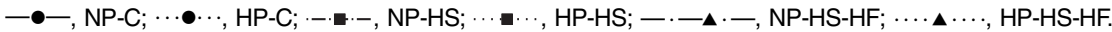

the HP diets (Table 4), but no effect of the composition of the diets on neuropeptide Y (NPY) expression was observed.

\section{Effect of high protein intake on hepatic gene expression profile (microarray analysis)}

The influence of HP content on the gene expression profile in the liver was determined by comparing each background diet (C, HS or HS-HF) with its HP counterpart.

Analysis of the expression profile of genes encoding amino acid (AA) transporters and enzymes that metabolise AA for energy supply suggests an induction of gluconeogenesis by HP feeding. For instance, we observed a strong up-regulation in the expression of solute carrier family 1 (glutamate/neutral amino acid transporter), member 4 (SLC1a4), which transports glutamate as well as transporters for cationic and neutral AA, under all HP conditions (Fig. 5(a)). On the other hand, most aminotransferases showed increased expression under all HP diets (Fig. 5(b)). Mitochondrial glutaminase 2 ( $G l s 2$ ) expression was mostly increased by HP under the two low-fat background diets ( $\mathrm{C}$ and HS) but less under HS-HF conditions. A similar pattern was observed for serine dehydratase $(S d s)$, proline dehydrogenase (Prodh) and methylcrotonoyl-CoA carboxylase $2 \beta$ (Mccc2). Finally, Pck1 expression, a key regulator of gluconeogenesis, was increased in livers of HP-fed rats as already detected by quantitative PCR. Expression of glucose-6-phosphatase (GGpc) was induced by HP under HS-HF conditions.

Genes encoding key enzymes of FA synthesis were downregulated by HP diets under all background diets (Fig. 5(d)). Expression of genes coding for enzymes involved in the control of 
(a)
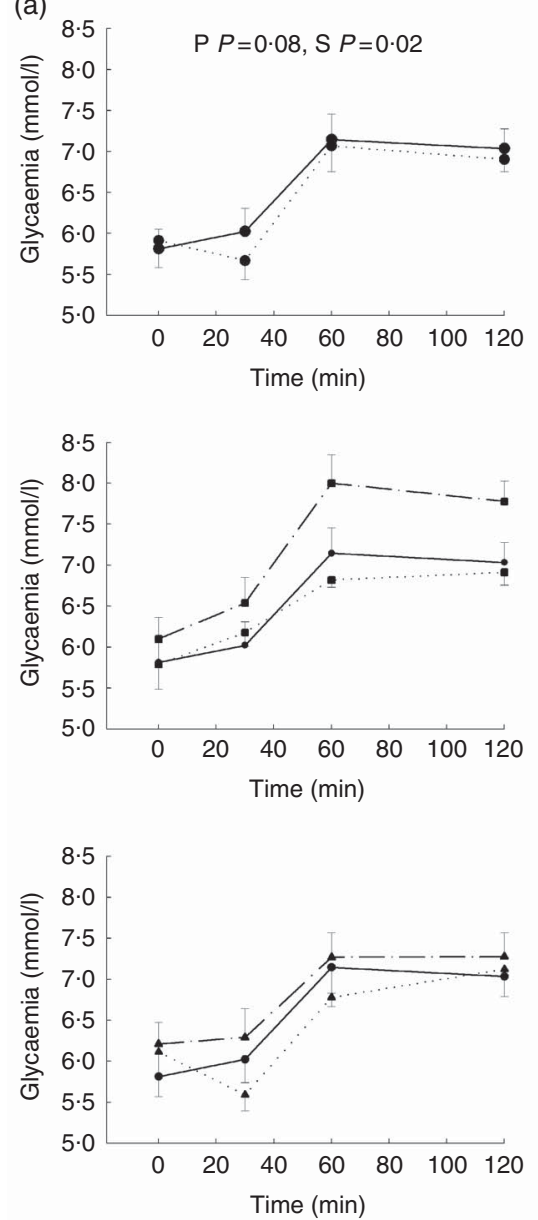

(d)

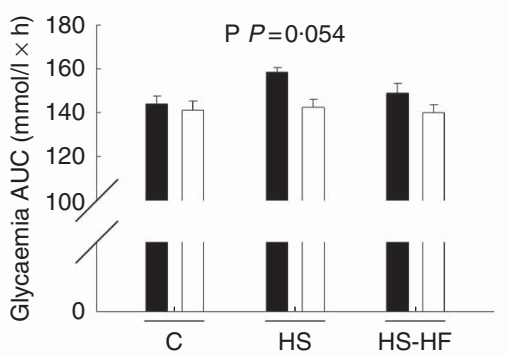

(b)
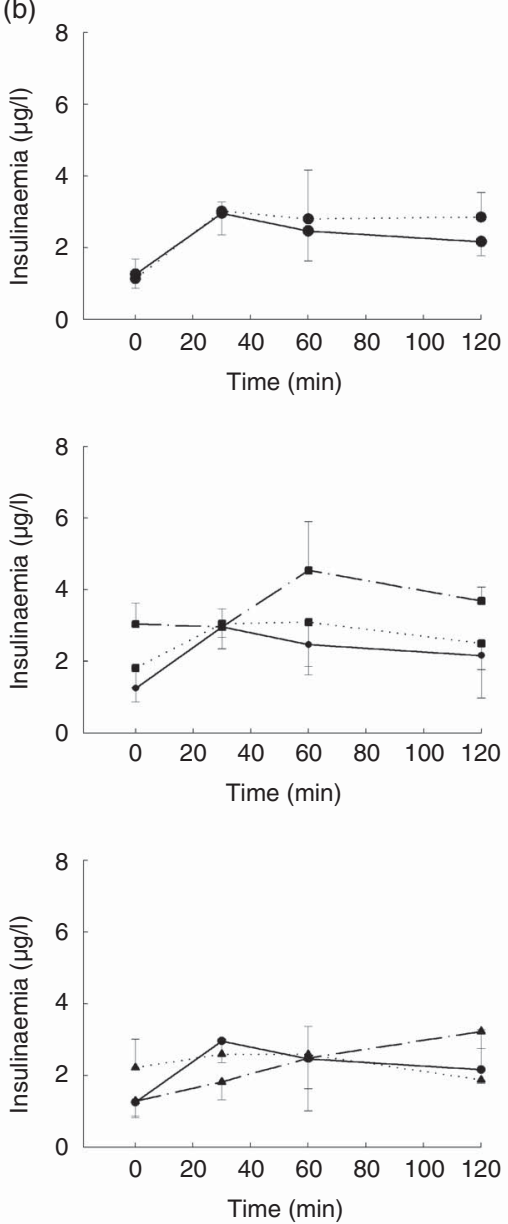

(e)

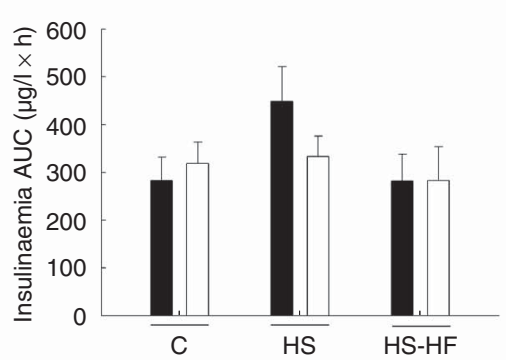

(c)
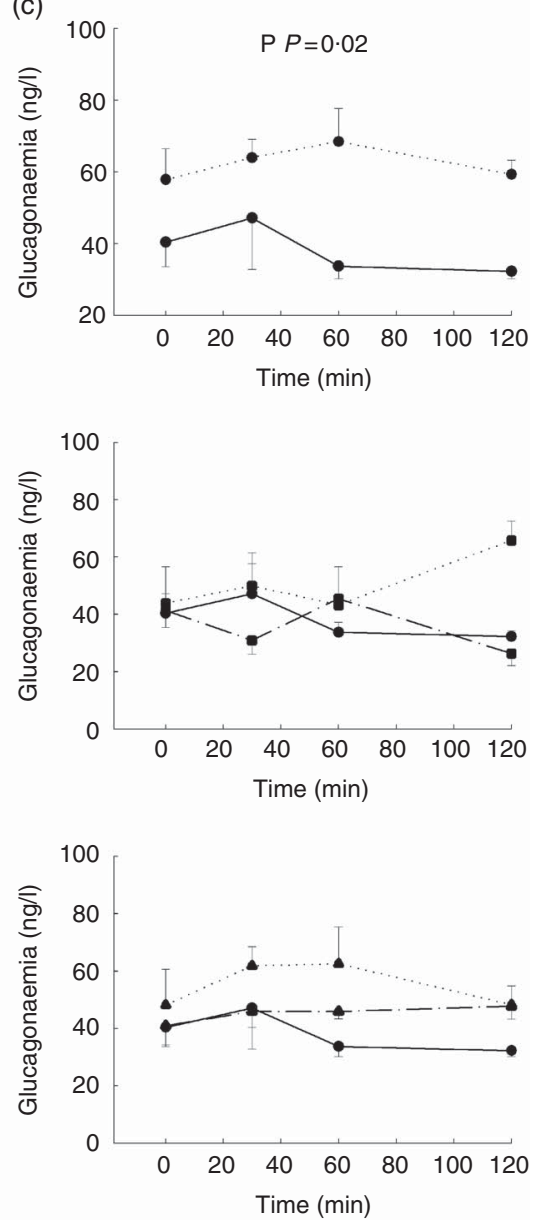

(f)

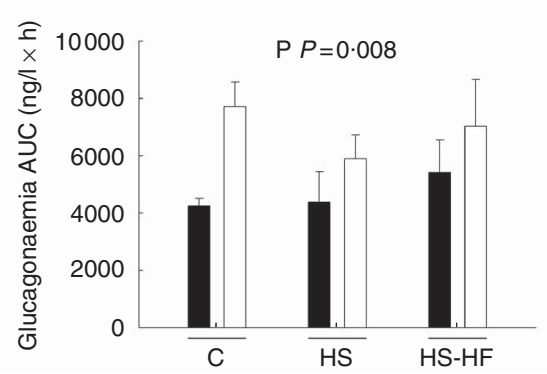

Fig. 4. Effect of high protein intake on glucose homoeostasis. From day 33 to 37 , rats were fed a calibrated meal, and blood was sampled at $t_{0}$ (fasted state) and at 30 , 60 and $120 \mathrm{~min}$ after the meal. Results are given as mean values with their standard errors for (a) glycaemia, (b) insulinaemia and (c) glucagonaemia. Kinetics of high protein (HP) groups were compared with normal protein (NP) groups for control (C), high sucrose (HS) or high sucrose and high fat (HS-HF), respectively. Results for AUC are given as mean values and standard deviations for glycaemia (d), insulinaemia (e) and glucagonaemia (f). The main statistical effects are indicated on each graph: the $P$ value is indicated when the difference was or tended to be significant. P, protein effect; $F$, fat effect; $S$, sucrose effect; $P \times F$, interaction between NP-HS-HF and HP-HS-HF; $\mathrm{P} \times \mathrm{C}$, interaction between NP-HS and HP-HS. NS indicates no significant statistical effect $(P>0.05)$. $-\bullet-$, NP-C;

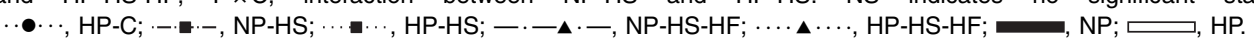

TAG synthesis was less modulated, except for mitochondrial glycerol-3-phosphate acyltransferase (Gpam) and acylglycerol3-phosphate O-acyltransferase 1 (Agpat1), which showed an increased expression but only under HS and HS-HF. It is, however, more difficult to conclude about the effects of HP diets on the regulation of $\beta$-oxidation because the picture (Fig. 5(e)) suggested either an increased translocation of FA into mitochondria for oxidation (up-regulation of acyl-CoA synthetase long-chain family member 3, carnitine acetyltransferase, carnitine palmitoyltransferase 1a, liver and $1 \mathrm{~b}$ for muscle; Acls3, Crat, Cpt1a and Cpt1b, respectively) or a lower oxidation of long-chain FA (down-regulation of hydroxyacyl-coenzyme A dehydrogenase, beta subunit; Hadhb).

HP diet also increased the expression of key genes of ketogenesis (Fig. 5(f)), but the expression of acetyl-coA acetyltransferase 1 (Acat1) involved in ketone body degradation was inhibited. In general, the highest changes in gene expression by HP were mostly found in the HS-HF group, which is in agreement with increased plasma $\beta$-HB levels. 
Table 3. Effect of high-protein (HP) diet on plasma parameters after meal test AUC and liver TAG content

(Mean values and standard deviations; $n$ )

\begin{tabular}{|c|c|c|c|c|c|c|c|c|c|c|c|c|c|}
\hline & \multicolumn{6}{|c|}{$\mathrm{NP}^{*}$} & \multicolumn{6}{|c|}{$\mathrm{HP}^{*}$} & \multirow[b]{3}{*}{ Statistical effect† } \\
\hline & \multicolumn{2}{|c|}{$C^{*}$} & \multicolumn{2}{|c|}{$\mathrm{HS}^{*}$} & \multicolumn{2}{|c|}{$\mathrm{HS}-\mathrm{HF}^{*}$} & \multicolumn{2}{|c|}{$\mathrm{C}^{*}$} & \multicolumn{2}{|c|}{$\mathrm{HS}^{*}$} & \multicolumn{2}{|c|}{ HS-HF* $^{*}$} & \\
\hline & Mean & SD & Mean & SD & Mean & SD & Mean & SD & Mean & SD & Mean & SD & \\
\hline Glycaemia $(g / l \times h)$ & $31 \cdot 1$ & $2 \cdot 05$ & $31 \cdot 3$ & 4.63 & 34.6 & 4.16 & 31.7 & $2 \cdot 90$ & $34 \cdot 0$ & 1.27 & $31 \cdot 2$ & 3.15 & $\mathrm{P}(P=0.054), \mathrm{F}(P<0.02)$ \\
\hline Glycerol $(\mu \mathrm{mol} / \mathrm{l} \times \mathrm{h})$ & $24 \cdot 2$ & $3 \cdot 1$ & $26 \cdot 2$ & $9 \cdot 1$ & 35.5 & 7.5 & $23 \cdot 9$ & $5 \cdot 1$ & $23 \cdot 6$. & $2 \cdot 3$ & $30 \cdot 8$ & 4.4 & NS \\
\hline TAG $(\mathrm{mmol} / \mathrm{l} \times \mathrm{h})$ & 114.8 & $26 \cdot 2$ & $107 \cdot 2$ & $37 \cdot 1$ & $212 \cdot 8$ & $61 \cdot 8$ & 72.4 & $17 \cdot 2$ & 79.7 & $18 \cdot 2$ & 111.6 & 18.9 & $\mathrm{P}(P<0.0001), \mathrm{F}(P<0.0001)$ \\
\hline Albumin $(g / l \times h)$ & $474 \cdot 1$ & $27 \cdot 9$ & 493.6 & $15 \cdot 5$ & $477 \cdot 0$ & 18.9 & 469.0 & $16 \cdot 6$ & 475.4 & $13 \cdot 8$ & 456.4 & 8.4 & NS \\
\hline Lactate $(\mathrm{mmol} / / \mathrm{l} \times \mathrm{h})$ & 406.5 & 78.4 & 551.7 & $210 \cdot 9$ & 378.3 & $76 \cdot 2$ & 371.1 & 131.9 & 387.6 & $56 \cdot 8$ & $346 \cdot 2$ & $105 \cdot 5$ & $\mathrm{~F}(P<0.02)$ \\
\hline Cholesterol (mmol/l ×h) & $205 \cdot 6$ & $21 \cdot 6$ & $222 \cdot 0$ & $30 \cdot 1$ & $211 \cdot 3$ & $15 \cdot 7$ & 230.5 & $58 \cdot 3$ & $212 \cdot 4$ & $49 \cdot 6$ & $232 \cdot 4$ & 38.0 & NS \\
\hline HDL-cholesterol (mmol/l×h) & 128.4 & $16 \cdot 8$ & 146.9 & $14 \cdot 2$ & $135 \cdot 6$ & $15 \cdot 5$ & $156 \cdot 2$ & $36 \cdot 8$ & $145 \cdot 2$ & $29 \cdot 2$ & 156.5 & 24.5 & $\mathrm{P}(P=0.055)$ \\
\hline$\beta$-Hydoxybutyrate $(\mathrm{mmol} / \mathrm{l} \times \mathrm{h})$ & $15 \cdot 7$ & $16 \cdot 8$ & 14.1 & $14 \cdot 2$ & 21.4 & $15 \cdot 5$ & $22 \cdot 1$ & $36 \cdot 8$ & $23 \cdot 0$ & $29 \cdot 2$ & $40 \cdot 2$ & 24.5 & $\mathrm{P}(P<0.02), \mathrm{F}(P=0.07)$ \\
\hline NEFA $(\mathrm{mmol} / \mathrm{l} \times \mathrm{h})$ & 54.8 & $9 \cdot 0$ & 63.5 & $26 \cdot 4$ & $92 \cdot 9$ & $21 \cdot 0$ & $62 \cdot 9$ & $16 \cdot 5$ & 61.5 & $7 \cdot 2$ & 93.9 & 23.4 & $\mathrm{~F}(P<0.001)$ \\
\hline Liver TAG (mg/g) & $24 \cdot 1$ & $5 \cdot 4$ & 21.1 & $7 \cdot 3$ & $24 \cdot 2$ & $4 \cdot 3$ & $18 \cdot 1$ & $3 \cdot 4$ & $18 \cdot 6$ & $2 \cdot 2$ & 23.7 & $5 \cdot 8$ & $\mathrm{~F}(P=0.07), \mathrm{P}(P=0.08)$ \\
\hline
\end{tabular}

$P$, protein effect; $F$, fat effect.

* Dietary treatment: NP, normal protein; HP; C, control; HS, high sucrose; HF, high fat.

† The $P$ value is indicated when the difference was or tended to be significant. NS indicates no significant statistical effect $(P>0.05)$.

Table 4. Effect of high-protein (HP) diet on hepatic, adipose and hypothalamic mRNA encoding key proteins involved in energy metabolism (Mean values and standard deviations; $n$ )

\begin{tabular}{|c|c|c|c|c|c|c|c|c|c|c|c|c|c|}
\hline \multirow[b]{3}{*}{ Relative expression } & \multicolumn{6}{|c|}{$\mathrm{NP}^{*}$} & \multicolumn{6}{|c|}{$\mathrm{HP}^{*}$} & \multirow[b]{3}{*}{ Statistical effect $\dagger$} \\
\hline & \multicolumn{2}{|c|}{$\mathrm{C}^{*}$} & \multicolumn{2}{|c|}{$\mathrm{HS}^{*}$} & \multicolumn{2}{|c|}{ HS-HF* } & \multicolumn{2}{|c|}{$\mathrm{C}^{*}$} & \multicolumn{2}{|c|}{$\mathrm{HS}^{*}$} & \multicolumn{2}{|c|}{ HS-HF* } & \\
\hline & Mean & SD & Mean & SD & Mean & SD & Mean & SD & Mean & SD & Mean & SD & \\
\hline \multicolumn{14}{|l|}{ Liver } \\
\hline Acaca & 1.0 & 0.3 & $1 \cdot 1$ & 0.4 & 0.9 & 0.5 & 0.8 & 0.5 & 0.6 & 0.2 & 0.3 & 0.1 & $\mathrm{P}(P<0.05)$ \\
\hline Acacb & 1.0 & 0.5 & $1 \cdot 8$ & $1 \cdot 1$ & $2 \cdot 0$ & 1.4 & $2 \cdot 3$ & 0.8 & 1.9 & 0.6 & 1.6 & 0.5 & NS \\
\hline Srebf-1c & 1.0 & 0.5 & 1.0 & 0.7 & 0.7 & 0.4 & 0.5 & 0.2 & 0.3 & 0.1 & 0.3 & 0.1 & $\mathrm{P}(P<0.05)$ \\
\hline Fasn & 1.0 & 0.9 & 0.7 & 0.5 & 0.8 & 0.5 & 0.7 & 0.5 & 0.4 & 0.2 & 0.4 & 0.3 & NS \\
\hline Cpt1a & 1.0 & 0.7 & 1.5 & $1 \cdot 1$ & 0.9 & 0.4 & $1 \cdot 3$ & 0.8 & 1.0 & 0.5 & 1.0 & 0.7 & NS \\
\hline Cpt2 & 1.0 & 0.3 & 1.3 & 0.2 & 1.0 & 0.3 & 1.3 & 0.6 & 1.3 & 0.2 & 1.3 & 0.4 & NS \\
\hline Ucp2 & 1.0 & 0.5 & $1 \cdot 7$ & 0.9 & $1 \cdot 1$ & 0.6 & 1.5 & 0.9 & $1 \cdot 2$ & 0.3 & 1.0 & 0.2 & NS \\
\hline Pck1 & 1.0 & 0.3 & 1.2 & 0.2 & 1.4 & 0.7 & 2.5 & 1.5 & $2 \cdot 0$ & 0.9 & $2 \cdot 7$ & 1.4 & $\mathrm{P}\left(\begin{array}{ll}P & 0.09\end{array}\right)$ \\
\hline \multicolumn{14}{|l|}{ Adipose tissue } \\
\hline Fasn & 1.0 & 0.5 & 0.7 & 0.5 & 0.3 & 0.3 & 0.4 & 0.4 & 0.6 & 0.4 & 0.3 & 0.2 & $\mathrm{~F}(P<0.05)$ \\
\hline Acaca & 1.0 & 0.5 & 0.6 & 0.5 & 0.5 & 0.2 & 0.6 & 0.4 & 0.7 & 0.5 & 0.2 & 0.1 & NS \\
\hline Lipe & 1.0 & 0.5 & 0.4 & 0.3 & 0.6 & 0.3 & 1.8 & $2 \cdot 0$ & 1.6 & 1.3 & 0.7 & 0.4 & NS \\
\hline Lpl & 1.0 & 0.3 & 0.8 & 0.9 & 0.7 & 0.1 & 0.8 & 0.3 & 0.9 & 0.5 & 0.7 & 0.3 & NS \\
\hline Leptin & 1.0 & 0.3 & 0.6 & 0.4 & 0.6 & 0.1 & 0.8 & 0.4 & 0.8 & 0.4 & 0.5 & 0.2 & $\mathrm{~S}\left(\begin{array}{ll}P & 0.09\end{array}\right)$ \\
\hline \multicolumn{14}{|l|}{ Hypothalamus } \\
\hline Npy & 1.0 & 0.7 & $1 \cdot 1$ & 0.3 & 0.8 & 0.2 & 0.8 & 0.43 & 1.0 & 0.5 & 1.0 & 0.6 & NS \\
\hline Pomc & 1.0 & 0.7 & 0.9 & 0.6 & 0.6 & 0.4 & 0.3 & 0.2 & 0.4 & 0.2 & 0.3 & 0.1 & $\mathrm{P}(P<0.05)$ \\
\hline
\end{tabular}

Acaca, acetyl-CoA carboxylase a; P, protein effect; Acacb, acetyl-CoA carboxylase b; Srebf-1c, sterol regulatory element binding transcription factor $1 ;$ Fasn, fatty acid synthase; Cpt1a, carnitine palmitoyltransferase 1a, liver; Cpt2, carnitine palmitoyltransferase 2; Ucp2, uncoupling protein 2; Pck1, phosphoenolpyruvate carboxykinase 1 (soluble); F, fat effect; Lipe, hormone-sensitive lipase; $L p l$, lipoprotein lipase; S, sucrose effect; $N p y$, neuropeptide Y; Pomc, pro-opiomelanocortin.

Gene expression was calculated as $2^{-\Delta \Delta C t}$ relative to the NP-C group and expressed as relative values normalised with $18 \mathrm{~S}$.

* Dietary treatment: NP, normal protein; HP; C, control; HS, high sucrose; HF, high fat.

$\dagger$ The $P$ value is indicated when the difference was or tended to be significant. NS indicates no significant statistical effect $(P>0.05)$.

Expression of genes encoding enzymes for cholesterol metabolism was almost exclusively up-regulated by the HP diets (Fig. 5(g)). This up-regulation was highest when rats were fed $\mathrm{C}$ and $\mathrm{HS}$ diets. Moreover, gene expression of enzymes catalysing bile acid synthesis was only slightly changed (Fig. 5(h)).

Relevant pathways are summarised in Fig. 5(i). A complete list of genes in their relevant pathways can be found in online Supplementary Fig. S2 and S3.

\section{Discussion}

The objective of this study was to assess the effect of highprotein diets on fat deposition induced by HS and HS-HF diets. For that purpose, rats were fed diets containing normal (C) or high amounts of sucrose (HS), or diets with either fat and sucrose (HS-HF), each of these diets with a normal or high protein content (NP or HP). Weight gain and adiposity did not differ for HS-HF and HS diets after 5 weeks of dietary treatment. 
(a)

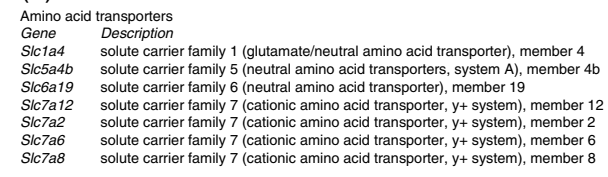

(b)

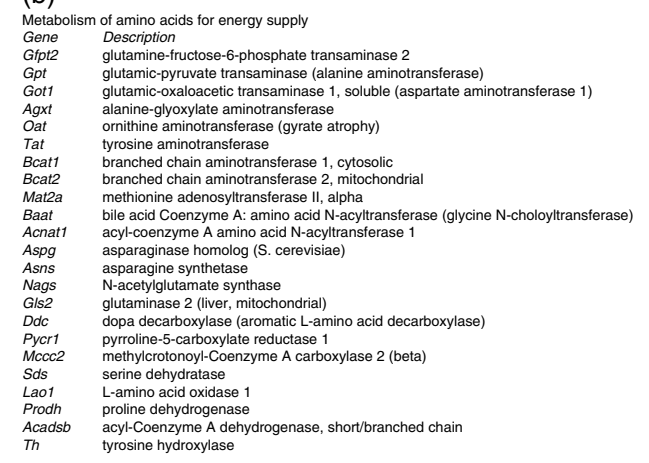

(c)

HP diets limited adiposity gain induced by both the HS and the HS-HF diet, which cannot be attributable to a decrease in food intake as no changes were observed between the different diets, despite a decrease in plasma ghrelin level in the HP groups. Gene expression analysis showed that HP intake reduced expression of genes involved in lipogenesis and stimulated ketone body production by the liver, particularly when HP was associated with HS-HF intake. Taken together, this suggests that under HP feeding, the induction of ketogenesis channels the excess of AA and fat to indirect oxidation, thereby lowering dietary lipid deposition and adiposity gain.

As expected, a reduction in food intake was observed during the first $3 \mathrm{~d}$ after the transition to HP $\operatorname{diet}^{(7,17)}$; however, we also observed no decrease in cumulative energy intake after 5 weeks, which is in accordance with other results in mice ${ }^{(1)}$. Leptin is an anorexigenic hormone secreted by the AT in proportion to its mass and it signals the hypothalamus about the energy stores status. Leptin induces opposite effects on two arcuate (ARC) nuclei neuronal subpopulations by inhibiting the orexigenic NPY/Agouti-related peptide neurons and stimulating (e)
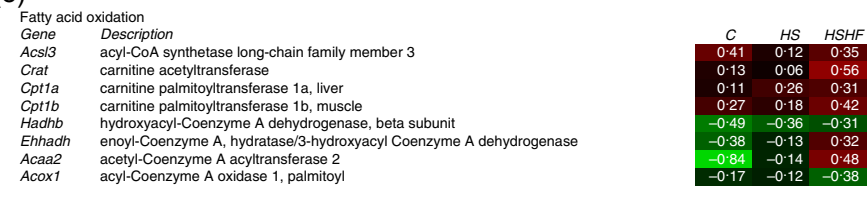

(f)
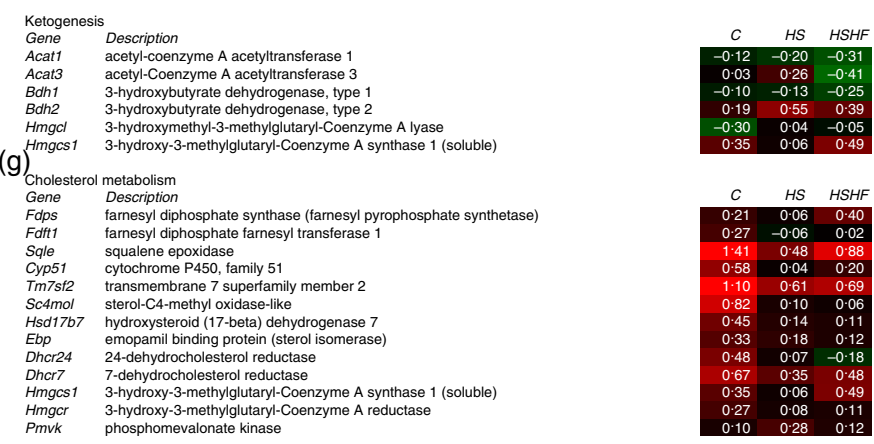

(h) Bile acid synthesis
Gene Description

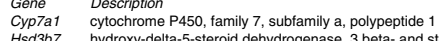
Hsd3b7 hydroxy-delta-5-steroid dehydrogenase, 3 beta- and 1
Cyp8b1 cytochrome P450, family 8, subfamily b, polypeptide 1 Akr1c1 aldo-keto reductase family 1, member C1
Akr1c2 aldo-keto reductase family 1, member C2

$\begin{array}{ll}\text { Akr1c2 } & \text { aldo-keto reductase family 1, member } \mathrm{C2} \\ \text { Baat } & \text { bile acid Coenzyme A: amino acid N-acyltransferase (glycine } \mathrm{N} \text {-choloyltransferase) }\end{array}$

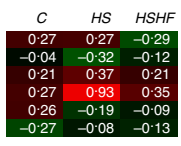

(i)

Summary of relevant pathways

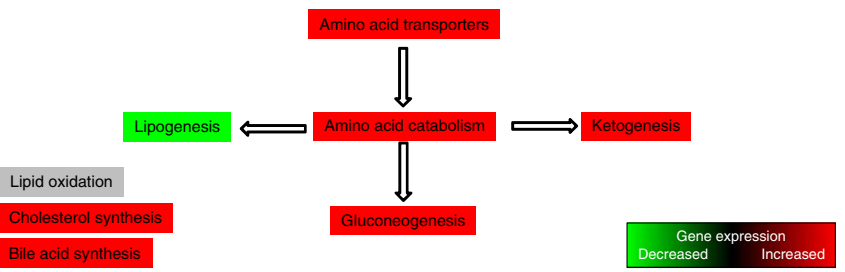

Fig. 5. Heatmaps of genes encoding (a) amino acids transporters, (b) enzymes involved in metabolism of amino acids for energy supply, (c) gluconeogenesis, (d) fatty acid and TAG synthesis, (e) fatty acid oxidation, (f) ketogenesis, (g) cholesterol metabolism and (h) bile acid synthesis. Fold changes are based on signal log ratios for each of the background high protein normal protein (HP-NP) diets. Values
values $<0$ represent decrease in gene expression under HP conditions.

the activity of anorexigenic POMC neurons ${ }^{(18,19)}$. Thus, the decrease in POMC mRNA observed in the present experiment, $2 \mathrm{~h}$ after ingestion of an HP meal, could be related to the decreased levels of plasma leptin that we observed in HP-fed rats. However, in a previous experiment, we observed that an HP diet (50\% protein-enriched diet) increased POMC mRNA levels in both ad libitum-fed and $12 \mathrm{~h}$ fasted rats ${ }^{(20,21)}$. These discrepancies can be explained by a different time of hypothalamic collection ( $2 \mathrm{~h}$ after ingestion of a meal fed after an overnight fast $v$. in this study $v$. ad libitum conditions previously) and the duration of the HP diet, which was longer in this study than in previous ones. Ghrelin is an orexigenic gut peptide that generally stimulates food intake by targeting neural pathways in the central nervous system including the hypothalamus and in the long-term increases fat mass ${ }^{(22)}$. It has been reported that intracerebroventricular administration of ghrelin did not induce hyperphagia when rats were fed an HF diet and gained adiposity ${ }^{(23)}$. Thus, in our study, the lack of an effect due to decrease in plasma ghrelin levels on food intake could be related to the adiposity. Moreover, the role of ghrelin in the 
increase of food intake in response to HF diet remains to be clarified, given that the ablation of ghrelin cell in transgenic mice did not decrease food intake ${ }^{(24)}$. It can, therefore, be concluded that the observed decrease in adiposity induced by the HP diets in this study was not due to the effect of proteins on food intake.

Body FA primarily stored in AT originate from dietary TAG and FA and from de novo synthesis of FA in the liver and AT. Between meals, when glucose availability decreases, stored TAG are lipolysed by lipoprotein lipase (LPL) to release FA to cover energy requirements. Results from targeted gene expression analysis and gene expression profiling showed that the main process involved in the reduced adiposity of HP-fed rats is the reduced hepatic lipogenesis (Fasn, Acaca, Acacb, Srebf-1c) from carbohydrates, whereas adipose LPL expression was not affected. The signals at the origin of this lower expression of lipogenic enzymes could be related to a lower increase in post-prandial glycaemia, but also to other AA- and hormone-derived signalling pathways ${ }^{(8-11)}$. No major changes were observed for insulin sensitivity during OGTT.

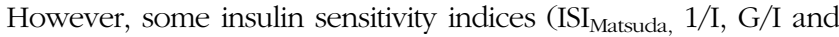
QUICKI $\left.{ }^{(13)}\right)$ tended to be higher in the NP-HS-HF group than in the other groups (data not shown), which suggests that an increase in the fat content of the diet decreases whole-body insulin sensitivity and that this increase was prevented by increasing the protein level of the diet. This result is also in line with the lower plasma TAG levels observed in the HP-fed rats of this study. Interestingly, we observed that lipogenesis in AT was also lower in HS-HP-fed rats compared with NP-fed animals (conditions where lipogenesis was induced), but this effect of HP feeding was not observed in HS-HF-fed animals because lipogenesis was low under HF feeding. Taken together, these observations indicate that lipogenesis is mainly lowered by protein in the liver, whereas in AT it is lowered by both fat and protein.

In response to protein excess, the protein pool remains unchanged because of the regulation of protein homoeostasis that maintains the stability of lean mass. These regulations include AA oxidation and interconversions as indicated by the increased expression of several transaminases and a general up-regulation of genes encoding enzymes involved in gluconeogenesis. However, the size of the glycogen pool is limited, which limits the possibility to convert AA to glucose and push the conversion of ketogenic AA towards ketone production $^{(9,25,26)}$. Accordingly, we observed an increase in plasma ketone body concentration in all HP groups, more drastically when HP was associated with HF intake. This result is in favour of the role of ketogenesis in energy homoeostasis maintenance in the context of HP feeding. However, there is no clear induction of key genes of ketogenesis, suggesting that this metabolic process is controlled by short-term processes. According to this hypothesis, the intake of a diet rich in ketogenic essential AA inhibits hepatic lipogenesis and avoids the development of hepatic steatosis ${ }^{(27,28)}$. Moreover, HP diet $(60 \%$ in casein) increases 'branched chain $\alpha$-cetoacids' in the blood and in organs ${ }^{(29)}$. The conversion of AA into ketone bodies or cetoacids could thus prevent the storage of AA carbon skeletons as lipids. Indeed, the stimulation of ketogenesis following an HP diet with low or high content of fat represents a way of by-passing storage of the energy, and thus prevents adiposity. Recent data about plasma metabolomic analysis of rats confirmed an increase in $\beta$-HB as a biomarker of HP intake ${ }^{(30)}$. However, there was no clear induction of key genes of ketogenesis, suggesting that this metabolic process is controlled by short-term post-transcriptional processes.

In conclusion, HP intake may reduce de novo synthesis of FA through a decrease in the expression of enzymes involved in lipogenesis, but also through poor utilisation of AA-derived carbon skeleton in lipogenic pathways. These results suggest that the increase in protein intake reduced fat deposition through the inhibition lipogenesis in the liver and AT. In parallel, the increase in plasma $\beta$-HB concentration suggests a stimulation of liver ketogenic pathways in which not only AA but also FA-derived carbon skeletons could be channelled at the expense of FA synthesis and deposition.

\section{Acknowledgements}

The authors acknowledge Mechteld Grootte Bromhaar, Division of Human Nutrition, Wageningen University, for her skilful technical assistance with the microarray analysis.

This work was supported by UMR914 funds.

D. T. and G. F. designed the research protocol; C. C., P. C. E., A. S.-F., J. P. and D. A.-M. conducted the research analysis; J. S. carried out the transcriptomique analysis; D. A.-M. and J. S. analysed the data; D. A.-M., J. S., C. C. and D. T. wrote the manuscript; and D. A.-M. and D. T. had the primary responsibility for the final content. All authors have read and approved the submitted manuscript.

C. C., P. C. E., J. S., A. S.-F., J. P., G. F., D. A.-M. and D. T. have no conflicts of interest.

\section{Supplementary material}

For supplementary material/s referred to in this article, please visit http://dx.doi.org/10.1017/S000711451500238X

\section{References}

1. Xiao F, Huang Z, Li H, et al. (2011) Leucine deprivation increases hepatic insulin sensitivity via GCN2/mTOR/S6K1 and AMPK pathways. Diabetes 60, 746-756.

2. Della-Pace ID, Rambo LM, Ribeiro LR, et al. (2013) Triterpene 3beta, 6beta, 16beta trihidroxilup-20(29)-ene protects against excitability and oxidative damage induced by pentylenetetrazol: the role of $\mathrm{Na}(+), \mathrm{K}(+)$-ATPase activity. Neuropharmacology 67, 455-464.

3. Kawai HD, La M, Kang HA, et al. (2013) Convergence of nicotine-induced and auditory-evoked neural activity activates ERK in auditory cortex. Synapse 67, 455-468.

4. Raymond F, Wang L, Moser M, et al. (2013) Consequences of exchanging carbohydrates for proteins in the cholesterol metabolism of mice fed a high-fat diet. PLOS ONE 7, e49058.

5. Rietman A, Schwarz J, Tome D, et al. (2014) High dietary protein intake, reducing or eliciting insulin resistance? Eur J Clin Nutr 68, 973-979.

6. Jean C, Rome S, Mathe V, et al. (2001) Metabolic evidence for adaptation to a high protein diet in rats. J Nutr 131, 91-98.

7. Bensaid A, Tome D, L'Heureux-Bourdon D, et al. (2003) A high-protein diet enhances satiety without conditioned taste aversion in the rat. Physiol Behav 78, 311-320. 
8. Blouet C, Mariotti F, Azzout-Marniche D, et al. (2006) The reduced energy intake of rats fed a high-protein low-carbohydrate diet explains the lower fat deposition, but macronutrient substitution accounts for the improved glycemic control. J Nutr 136, 1849-1854.

9. Stepien M, Gaudichon C, Fromentin G, et al. (2011) Increasing protein at the expense of carbohydrate in the diet downregulates glucose utilization as glucose sparing effect in rats. PLOS ONE 6, e14664.

10. Brito MN, Brito NA, Brito SR, et al. (1999) Brown adipose tissue triacylglycerol synthesis in rats adapted to a high-protein, carbohydrate-free diet. Am J Physiol 276, R1003-R1009.

11. Schwarz J, Tome D, Baars A, et al. (2012) Dietary protein affects gene expression and prevents lipid accumulation in the liver in mice. PLOS ONE 7, e47303.

12. Pichon L, Huneau JF, Fromentin G, et al. (2006) A highprotein, high-fat, carbohydrate-free diet reduces energy intake, hepatic lipogenesis, and adiposity in rats. J Nutr 136, 1256-1260.

13. Muniyappa R, Lee S, Chen H, et al. (2008) Current approaches for assessing insulin sensitivity and resistance in vivo: advantages, limitations, and appropriate usage. Am J Physiol Endocrinol Metab 294, E15-E26.

14. Lin K, Kools H, de Groot PJ, et al. (2011) MADMAX management and analysis database for multiple omics experiments. J Integr Bioinform 8, 160.

15. Dai M, Wang $\mathrm{P}$, Boyd $\mathrm{AD}$, et al. (2005) Evolving gene/ transcript definitions significantly alter the interpretation of GeneChip data. Nucleic Acids Res 33, e175.

16. Irizarry RA, Hobbs B, Collin F, et al. (2003) Exploration, normalization, and summaries of high density oligonucleotide array probe level data. Biostatistics $\mathbf{4}, 249-264$.

17. Journel M, Chaumontet C, Darcel N, et al. (2012) Brain responses to high-protein diets. Adv Nutr 3, 322-329.

18. Cowley MA, Smart JL, Rubinstein M, et al. (2001) Leptin activates anorexigenic POMC neurons through a neural network in the arcuate nucleus. Nature 411, 480-484.

19. Qiu J, Fang Y, Ronnekleiv OK, et al. (2010) Leptin excites proopiomelanocortin neurons via activation of TRPC channels. J Neurosci 30, 1560-1565.
20. Faipoux R, Tome D, Gougis S, et al. (2008) Proteins activate satiety-related neuronal pathways in the brainstem and hypothalamus of rats. J Nutr 138, 1172-1178.

21. Ropelle ER, Pauli JR, Fernandes MF, et al. (2008) A central role for neuronal AMP-activated protein kinase (AMPK) and mammalian target of rapamycin (mTOR) in high-protein dietinduced weight loss. Diabetes 57, 594-605.

22. Theander-Carrillo C, Wiedmer P, Cettour-Rose P, et al. (2006) Ghrelin action in the brain controls adipocyte metabolism. J Clin Invest 116, 1983-1993.

23. Perez-Tilve D, Heppner K, Kirchner H, et al. (2011) Ghrelin-induced adiposity is independent of orexigenic effects. FASEB J 25, 2814-2822.

24. McFarlane MR, Brown MS, Goldstein JL, et al. (2014) Induced ablation of ghrelin cells in adult mice does not decrease food intake, body weight, or response to high-fat diet. Cell Metab 20, 54-60.

25. Fromentin C, Azzout-Marniche D, Tome D, et al. (2011) The postprandial use of dietary amino acids as an energy substrate is delayed after the deamination process in rats adapted for 2 weeks to a high protein diet. Amino Acids 40, 1461-1472.

26. Stepien M, Gaudichon C, Azzout-Marniche D, et al. (2010) Postprandial nutrient partitioning but not energy expenditure is modified in growing rats during adaptation to a highprotein diet. J Nutr 140, 939-945.

27. Noguchi Y, Nishikata N, Shikata N, et al. (2010) Ketogenic essential amino acids modulate lipid synthetic pathways and prevent hepatic steatosis in mice. PLOS ONE 5, e12057.

28. Nishikata N, Shikata N, Kimura Y, et al. (2011) Dietary lipid-dependent regulation of de novo lipogenesis and lipid partitioning by ketogenic essential amino acids in mice. Nutr Diabetes 1, e5.

29. Hutson SM \& Harper AE (1981) Blood and tissue branched-chain amino and alpha-keto acid concentrations: effect of diet, starvation, and disease. Am J Clin Nutr 34, 173-183.

30. Mu C, Yang Y, Luo Z, et al. (2015) Metabolomic analysis reveals distinct profiles in the plasma and urine of rats fed a high-protein diet. Amino Acids 47, 1225-1238. 